\title{
Comparison of different techniques for purification of triamcinolone acetonide suspension for intravitreal use
}

\author{
J García-Arumí, A Boixadera, J Giralt, V Martinez-Castillo, F Gomez-Ulla, B Corcostegui, \\ E García-Arumí
}

Br J Ophthalmol 2005;89:1112-1114. doi: 10.1136/bjo.2005.067744

\begin{abstract}
Background: Intravitreal triamcinolone has increasingly been used for the treatment of oedematous and neovascular diseases and purification of triamcinolone suspension may be important in order to avoid the potential toxic effects of the vehicle. The aim was to evaluate different techniques used to reduce the solvent agent benzyl alcohol $(9.9 \mathrm{mg} / \mathrm{ml})$ from a commercially prepared triamcinolone acetonide suspension. Methods: Different techniques were used to reduce the solvent agent benzyl alcohol: filter techniques using $0.22 \mu \mathrm{m}$ or $5 \mu \mathrm{m}$ pore size, and non-filter techniques using sedimentation or centrifugation. Quantification of triamcinolone acetonide and benzyl alcohol was performed by high pressure liquid chromatography (HPLC).

Results: Benzyl alcohol concentration was decreased significantly in all the techniques used compared with the original commercial suspension $(p<0.05)$, with no significant differences among them. The reduction was approximately one tenth of its original concentration. However, triamcinolone acetonide concentration differed significantly depending on the method used. Centrifugation method showed no differences versus the original commercial solution; sedimentation technique reduced the expected dose only $25 \%$; the filter technique using a $5 \mu \mathrm{m}$ pore size membrane reduced the expected dose to one fourth, while the filter technique using a $0.22 \mu \mathrm{m}$ pore size membrane reduced the expected dose to $45 \%$.

Conclusions: All the different techniques employed effectively reduced the concentration of benzyl alcohol. However, the final concentration of triamcinolone was much lower than expected using the filter techniques. The pore size membrane inversely influenced the final concentration, with part of the triamcinolone crystals probably being entrapped in the filter. Centrifugation is recommended as the best way of administering the drug.
\end{abstract}

\footnotetext{
C
} linical and experimental studies have shown that the intravitreal injection of triamcinolone acetonide may be a therapeutic option for neovascular, oedematous, or inflammatory diseases. ${ }^{1-4}$ The use of different doses of intravitreal triamcinolone and different techniques to reduce the solvent agent, primarily benzyl alcohol, from a commercially prepared triamcinolone acetonide suspension have been reported. ${ }^{56}$ We conducted this study to quantify by high pressure liquid chromatography (HPLC) triamcinolone acetonide and benzyl alcohol concentration after using different techniques to reduce the solvent agent.

\section{MATERIAL AND METHODS}

Different techniques applied to reduce the solvent agent benzyl alcohol $(9.9 \mathrm{mg} / \mathrm{ml})$ from a commercially prepared triamcinolone acetonide suspension (Trigon Depot; $40 \mathrm{mg} / \mathrm{ml}$, Bristol-Myers Squibb SL, New York, NY, USA) were evaluated.

\section{Non-filter techniques}

Two different non-filter techniques were used: sedimentation and centrifugation. Commercially prepared triamcinolone acetonide suspension was allowed to sediment overnight and $0.9 \mathrm{ml}$ of the supernatant were extracted with a tuberculin syringe. The pellet was resuspended with 0.9 or $0.5 \mathrm{ml}$ of balanced salt solution (BSS) (Alcon Laboratories Inc, Texas, USA). In the other non-filter technique, the commercial suspension was centrifuged at $3000 \times \mathrm{g}$ for 5 minutes; $0.9 \mathrm{ml}$ of the supernatant were extracted with a tuberculin syringe and the pellet resuspended with $1 \mathrm{ml}$ of BSS.

\section{Filter techniques}

The triamcinolone had been prepared by taking $0.62 \mathrm{ml}$ from the commercial triamcinolone acetonide ampule, following the technique described by Jonas. ${ }^{7}$ The extracted volume was placed in a tuberculin syringe $(1 \mathrm{ml})$ filled with Ringer lactate solution (Laboratorios Grifols SA, Barcelona, Spain). Two different syringe driven filter units were evaluated: a Millipore filter (Millex-GS $0.22 \mu \mathrm{m}$ pore size; Millipore Co, Cork, Ireland) and a Pall filter (Versapor Membrane $5 \mu \mathrm{m}$ pore size, Pall Corporation, MI, USA). The selected filter was placed on the top of the syringe and most of the contents of the syringe were pressed through the filter, with the triamcinolone crystals remaining in the syringe. The syringe was refilled with Ringer lactate solution and the same procedure was repeated three times. At the end, $0.2 \mathrm{ml}$ of the solution were left in the syringe.

\section{Triamcinolone acetonide and benzyl alcohol quantification}

Triamcinolone acetonide and benzyl alcohol quantification was performed using a modification of the Matysova method. ${ }^{8}$ Ten $\mu \mathrm{l}$ of the suspension obtained by the different techniques and $10 \mu \mathrm{l}$ of the commercial suspension were diluted with $3 \mathrm{ml}$ of acetonitrile and water (40/60 v/v). Ten $\mu \mathrm{l}$ of the resulting dilution were injected into the HPLC system (Alliance 2695 Waters Corporation, Milford, MA, USA). Reversed phase HPLC was performed at room temperature. The mobile phase was a mixture of acetonitrile and water $(40 / 60 \mathrm{v} / \mathrm{v})$. The column used was a Symmetry $\mathrm{C}_{18}(5 \mu \mathrm{m})$ $(150 \times 4.6 \mathrm{~mm}$ ID) (Waters Corporation), and a guardcolumn Symmetry $\mathrm{C}_{18}(5 \mu \mathrm{m}) \quad(20 \times 3.9 \mathrm{~mm}$ ID), (Waters Corporation). The flow rate was $0.8 \mathrm{ml} / \mathrm{min}$ and the eluate was monitored at a $240 \mathrm{~nm}$ with a Waters 2487 detector (Waters Corporation) and quantified based on comparison with a calibration curve of triamcinolone

Abbreviations: BSS, balanced salt solution; HPLC, high pressure liquid chromatography. 
acetonide and benzyl alcohol. Identification of peaks was based on the comparison of retention times of compounds in standard solutions. Data were processed with Millenium software (Waters Corporation).

\section{Statistical analyses}

The non-parametric Kruskal-Wallis test and Mann-Whitney $\mathrm{U}$ test were performed for comparisons among the different techniques. Results are expressed as mean (standard deviation). Statistical significance was set at $p<0.05$. Statistics were performed using the Statgraphics software package (Manugistics Inc, Herndorn, VA, USA).

\section{RESULTS}

The benzyl alcohol concentration obtained using the different methods is shown in figure 1 . Benzyl alcohol concentration was decreased significantly in all the techniques used compared with the original commercial suspension $(p<0.05)$. No statistically significant differences were found among the different methods used to reduce the solvent agent; the reduction was about one tenth of its original concentration.

We were also interested in studying the effect of these procedures on triamcinolone acetonide concentration. Triamcinolone acetonide concentration obtained with the different methods is shown in figure 2. The centrifugation method showed no differences versus the original commercial solution. However, two techniques (filter technique using a Millex-GS $0.22 \mu \mathrm{m}$ pore size membrane and sedimentation technique with resuspension with $0.5 \mathrm{ml}$ BBS (half of the original volume)) presented significantly higher triamcinolone acetonide concentration (an increase of about 1.5) than in the original commercial solution $(\mathrm{p}<0.05)$. Moreover, a significantly decreased triamcinolone acetonide concentration (around $75 \%$ of the original concentration) was obtained with the filter technique using a Versapor Membrane $5 \mu \mathrm{m}$ pore size membrane and with the sedimentation technique and resuspension with $0.9 \mathrm{ml}$ BSS (original volume)

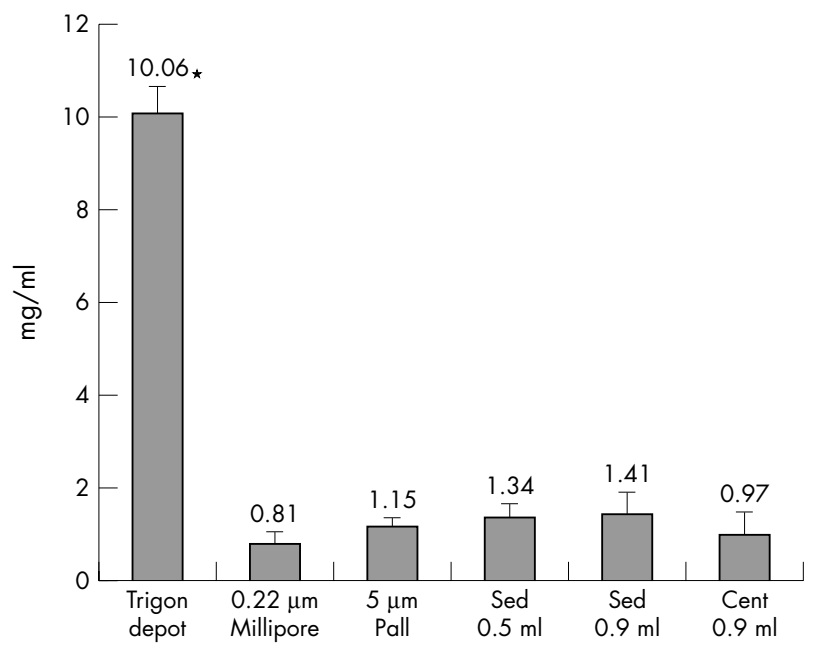

Figure 1 Benzyl alcohol measured by high pressure liquid chromatography. Trigon depot, benzyl alcohol concentration in the original resuspended Trigon ampule; $0.22 \mu \mathrm{m}$ Millipore and $5 \mu \mathrm{m}$ Pall; benzyl alcohol concentration after the corresponding filter techniques; Sed $0.5 \mathrm{ml}$ and Sed $0.9 \mathrm{ml}$, benzyl alcohol concentration after the corresponding sedimentation technique and pellet reconstitution with 0.5 or $0.9 \mathrm{ml}$ of BBS; Cent $1 \mathrm{ml}$, benzyl alcohol concentration after the corresponding centrifugation technique. Bars are means of three independent assays performed in duplicate. Errors bars represent standard deviations. *Benzyl alcohol was statistically significantly higher in Trigon depot than in the techniques used to reduce the solvent agent $(p<0.05)$.

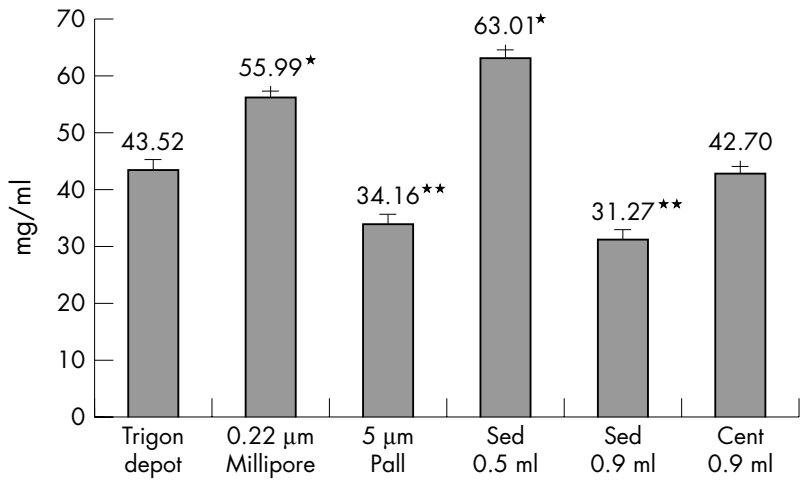

Figure 2 Triamcinolone acetonide measured by high pressure liquid chromatography. Trigon depot, triamcinolone acetonide concentration in the original resuspended Trigon ampule; $0.22 \mu \mathrm{m}$ Millipore and $5 \mu \mathrm{m}$ Pall, triamcinolone acetonide concentration after the corresponding filter techniques; Sed $0.5 \mathrm{ml}$ and Sed $0.9 \mathrm{ml}$, triamcinolone acetonide concentration after the corresponding sedimentation technique and pellet reconstitution with 0.9 or $0.5 \mathrm{ml}$ of BBS; Cent $1 \mathrm{ml}$, triamcinolone concentration after the corresponding centrifugation technique. Bars are means of three independent assays performed in duplicate. Errors bars represent standard deviations. *Triamcinolone acetonide concentration statistically significantly higher than Trigon depot, ${ }^{* *}$ Statistically significantly lower than Trigon depot $(p<0.05)$.

$(p<0.05)$. The coefficient of variation was $7 \%$ for the commercial solution and lower than $15 \%$ for the different methods.

\section{DISCUSSION}

Intravitreal triamcinolone acetonide has increasingly been used in pilot studies for the treatment of oedematous, proliferative, and neovascular diseases. ${ }^{1-4}$ Some investigators have found that the vehicle, not the crystalline cortisone itself, could be toxic for intraocular tissue. ${ }^{9}$ Benzyl alcohol has been implicated in cases of sterile endophthalmitis after intravitreal injection, and in aseptic meningitis following intrathecal administration. ${ }^{10}{ }^{11}$ As a result of the possible toxicity of benzyl alcohol, various techniques employed to reduce the solvent agent have been reported. ${ }^{56}$

Recently, Rodriguez-Coleman et al, ${ }^{12}$ after using the different published techniques to reduce the solvent agent and quantifying triamcinolone and benzyl alcohol by HPLC, surprisingly observed that the mean level of benzyl alcohol, instead of being reduced, increased three or fourfold. They explained the higher level of benzyl alcohol by its affinity for a lipophilic environment being in the triamcinolone fraction when they attempted to concentrate the triamcinolone crystals. Our results are opposite to those of RodriguezColeman et al, as the benzyl alcohol concentration was decreased significantly in all the techniques used compared with the original commercial suspension $(p<0.05)$, with the reduction being about one tenth of its original concentration. No statistically significant differences were found among the different methods.

However, the final triamcinolone doses differed notably depending on the cleansing technique employed. With the filter technique published by Jonas et al using a Versapor $5 \mu \mathrm{m}$ filter, the final mean dose of triamcinolone was $34 \mathrm{mg} /$ $\mathrm{ml}(6.8 \mathrm{mg}$ in $0.2 \mathrm{ml}$ instead of the $20-25 \mathrm{mg}$ in $0.2 \mathrm{ml}$ reported). ${ }^{5}$ Our results are very similar to those observed by Rodriguez-Coleman et al (6.5 mg in $0.2 \mathrm{ml})$. Using a smaller pore size $(0.22 \mu \mathrm{m})$, the final concentration increased $(56 \mathrm{mg} / \mathrm{ml})$, but was still $45 \%$ of the original concentration. The possible explanation for the drug loss is that part of the triamcinolone was entrapped in the filter and more easily when the pore was larger. These considerably lower than 
predicted doses of triamcinolone may lead to further evaluation of the published articles using this filter cleansing technique regarding the effectiveness, half life, and secondary effects of the intravitreally injected triamcinolone.

With the centrifugation and sedimentation techniques, the final dose was close to their target, with a $25 \%$ reduction using the latter technique. This loss of active drug may be corrected by resuspending the pellet with a lower BSS volume, as observed in our study with $0.5 \mathrm{ml}$ of saline solution.

Standardisation of the aspirated volume of the vehicle from the commercially available suspension (we recommend $0.9 \mathrm{ml}$ ) would be interesting in sedimentation and centrifugation methods to obtain the lowest benzyl alcohol concentration, although it would influence little the final triamcinolone concentration.

In conclusion we recommend, as the best way of administering the drug, a non-filtering technique, concretely the centrifugation at $3000 \times \mathrm{g}$ for 5 minutes with extraction of $0.9 \mathrm{ml}$ of the supernatant and the pellet resuspension with $0.9 \mathrm{ml}$ of BSS, as the final triamcinolone concentration remains almost unchanged

\section{Authors' affiliations}

J García-Arumí, A Boixadera, J Giralt, V Martinez-Castillo, E García-

Arumí, Vall d'Hebrón Hospital, Universidad Autónoma de Barcelona,

Barcelona, Spain

J García-Arumí, B Corcostegui, Instituto de Microcirugía Ocular,

Barcelona, Spain

F Gomez-Ulla, The Provincial de Conxo Hospital, Santiago de

Compostela, Spain

Competing interests: none declared
Correspondence to: Dr J García Arumí, Instituto de Microcirugía

Ocular, C/Munner n॰10, 08022, Barcelona, Spain;

17215jga@comb.es

Accepted for publication 1 April 2005

\section{REFERENCES}

1 Jonas JB, Hayler JK, Söfker A, et al. Regression of neovascular iris vessels by intravitreal injection of crystalline cortisone. J Glaucoma 2001;10:284-7.

2 Martidis A, Duker JS, Greenberg PB, et al. Intravitreal triamcinolone for refractory diabetic macular edema. Ophthalmology 2002;109:920-7.

3 Jonas JB, Kreissig I, Söfker A, et al. Intravitreal injection of intravitreal triamcinolone for diffuse diabetic macular edema. Arch Ophthalmol 2003;121:57-61.

4 Antcliff RJ, Spalton DJ, Stanford MR, et al. Intravitreal triamcinolone for uveitic cystoid macular edema: an optical coherence tomography study. Ophthalmology 2001;108:765-72.

5 Jonas JB, Kreissig I, Hugger $\mathrm{P}$, et al. Intravitreal triamcinolone acetonide for exudative age related macular degeneration. $\mathrm{Br} J$ Ophthalmol 2003;87:462-8.

6 Jonas JB, Hayler JK, Söfker A, et al. Intravitreal injection of crystalline cortisone as adjunctive treatment of proliferative diabetic retinopathy. Am J Ophthalmol 2001;131:468-71.

7 Jonas JB, Akkoyun I, Budde W M, et al. Intravitreal reinjection of triamcinolone for exudative age-related macular degeneration. Arch Ophthalmol 2004; 122:218-22.

8 Matisova L, Hájková R, Sicha J, et al. Determination of methylparaben, propylparaben, triamcinolone acetonide and its degradation product in a topical cream by RP-HPLC. Anal Bioanal Chem 2003;376:440-3.

9 Hida T, Chandler D, Arena JE, et al. Experimental and clinical observations of the intraocular toxicity of commercial corticosteroid preparations. Am J Ophthalmol 1986;101:190-5.

10 Sutter FKP, Gillies MC. Pseudo-endophthalmitis after intravitreal injection of Triamcinolone. Br J Ophthalmol 2003;87:972-4

11 Brown WJ, Buist NR, Gipson HT, et al. Fatal benzyl alcohol poisoning in a neonatal intensive unit. Lancet 1982;1:1250.

12 Rodriguez-Coleman $\mathbf{H}$, Yuan $\mathrm{P}, \mathrm{Kim} \mathrm{H}$, et al. Intravitreal injection of triamcinolone for diffuse macular edema. Arch Ophthalmol 2004; 112:1085-6.

\section{bmjupdates+}

bmiupdates+ is a unique and free alerting service, designed to keep you up to date with the medical literature that is truly important to your practice.

bmjupdates+ will alert you to important new research and will provide you with the best new evidence concerning important advances in health care, tailored to your medical interests and time demands.

Where does the information come from?

bmjupdates+ applies an expert critical appraisal filter to over 100 top medical journals A panel of over 2000 physicians find the few 'must read' studies for each area of clinical interest

Sign up to receive your tailored email alerts, searching access and more...

www.bmjupdates.com 